\begin{tabular}{|c|c|c|c|c|c|}
\hline $\begin{array}{l}\text { Learning } \\
\text { opportunities }\end{array}$ & $\begin{array}{l}\text { Strongly agree } \\
\mathrm{N}(\%)\end{array}$ & $\begin{array}{l}\text { Agree } \\
\text { N (\%) }\end{array}$ & $\begin{array}{l}\text { Neutral } \\
\text { N (\%) }\end{array}$ & $\begin{array}{l}\text { Disagree } \\
\text { N (\%) }\end{array}$ & $\begin{array}{l}\text { Strongly } \\
\text { disagree } \mathrm{N}(\%)\end{array}$ \\
\hline Basic sciences & $13(7.8)$ & $\begin{array}{l}46 \\
(27.7)\end{array}$ & $\begin{array}{l}41 \\
(24.7)\end{array}$ & $40(24.1)$ & $26(15.7)$ \\
\hline History taking & $37(22.3)$ & $\begin{array}{l}77 \\
(46.4)\end{array}$ & $\begin{array}{l}27 \\
(16.3)\end{array}$ & $16(9.6)$ & $9(5.4)$ \\
\hline $\begin{array}{l}\text { Physical } \\
\text { examination }\end{array}$ & $31(18.7)$ & $\begin{array}{l}72 \\
(43.4)\end{array}$ & $\begin{array}{l}28 \\
(16.9)\end{array}$ & $22(13.3)$ & $13(7.8)$ \\
\hline $\begin{array}{l}\text { Diagnostic } \\
\text { investigation }\end{array}$ & $49(29.5)$ & $\begin{array}{l}89 \\
(53.6)\end{array}$ & $\begin{array}{l}17 \\
(10.2)\end{array}$ & $5(3)$ & $6(3.6)$ \\
\hline $\begin{array}{l}\text { Patient } \\
\text { management }\end{array}$ & $52(31.3)$ & $\begin{array}{l}81 \\
(48.8)\end{array}$ & $\begin{array}{l}22 \\
(13.3)\end{array}$ & $7(4.2)$ & $4(2.4)$ \\
\hline Documentation & $27(16.3)$ & $\begin{array}{l}67 \\
(40.4)\end{array}$ & $\begin{array}{l}47 \\
(28.3)\end{array}$ & $20(12)$ & $5(3)$ \\
\hline $\begin{array}{l}\text { Time } \\
\text { management }\end{array}$ & $22(13.3)$ & $\begin{array}{l}64 \\
(38.6)\end{array}$ & $\begin{array}{l}48 \\
(28.9)\end{array}$ & $22(13.3)$ & $10(6)$ \\
\hline $\begin{array}{l}\text { Communication } \\
\text { skills }\end{array}$ & $45(27.1)$ & $78(47)$ & $\begin{array}{l}26 \\
(15.7)\end{array}$ & $10(6)$ & $7(4.2)$ \\
\hline
\end{tabular}

the bedside. The aim of this study was to assess trainees' perception of the educational value of WRs.

Methods All trainee doctors in specialties that perform WRs (e.g. medicine, surgery) at a large tertiary care teaching hospital between October and December 2019 were invited to complete a self-administered questionnaire.

Results Total of 162 trainees participated (response rate 66\%). Table 1 shows the sample's perceptions of learning knowledge, skills, or attitudes during WRs. The majority (52\%) reported that WRs are educationally very useful. Trainees generally agreed that WRs were a good opportunity to learn approaches to history taking $(68 \%)$ physical examination (62\%), diagnostics investigations (83\%) and patient management (80\%). The greatest barriers to learning on WRs were; lack of time (79\%), caseload (77\%), emphasis to get work done (66\%) and a busy ward environment (57\%).

Conclusions Majority of the trainee doctors perceived ward rounds as great opportunity for all domains of learning in diagnostics, patient management, history and physical examination while lack of time, caseload and busy environment identified as obstacles to this practice.

\section{P178 EVALUATING MEDICAL STUDENTS' TELEPHONE CLERKINGS IN THE RESPIRATORY PLACEMENT}

${ }^{1} \mathrm{~N}$ Rasmussen, ${ }^{1} \mathrm{M}$ Yakoub, ${ }^{1} \mathrm{~F}$ Simpson-Orlebar, ${ }^{2} \mathrm{~N}$ Marks. 'University College London, London, UK; ${ }^{2}$ Whittington Health NHS Trust, London, UK

\subsection{6/thorax-2021-BTSabstracts.287}

Introduction and Objectives The impact of the COVID-19 pandemic on undergraduate medical education has seen a reduced provision of learning opportunities, including face-to-face outpatient interaction. To facilitate active learning in the clinic component of the respiratory rotation, long-term patients known to the department consented to being contacted by medical students via telephone. Students elicited a telephone history, which they were able to subsequently present to their consultant supervisor for discussion and feedback. We aimed to evaluate this medium of student-patient interaction from both perspectives using survey-based responses.

Methods Two separate surveys were distributed between April and June 2021. All students who had participated in telephone history taking sessions were invited to complete an online survey. Patients were offered the choice to complete their survey via telephone, online, or on paper, with all choosing to respond via telephone call. The questionnaires employed a combination of discrete scales (e.g. the 5 point Likert scale) and free text responses.

Results 14/19 (74\%) responses from patients and 15/24 (63\%) responses from students were collected. A majority (89\%) of patients agreed that speaking to medical students was convenient for them, and most (71\%) would be inclined to engage in telephone conversations with students in the future. $100 \%$ of student responses agreed that conducting a telephone consultation helped improve their history taking ability, and the vast majority (93\%) agreed that the opportunity to present and discuss their history-taking was a valuable part of the learning experience. Free text responses elucidated the subtleties of what patients and students felt to be the mutual benefits of engaging in telephone consultations.

Conclusions The scheme provided a successful opportunity for students to practise their history taking and to adapt to the unique challenges of telephone consulting. Patients reported that talking to medical students was a positive and rewarding experience. It is possible that patients and students who found their participation in the scheme to be a more negative experience were less likely to take part in feedback. These findings contain lessons for developing undergraduate education in the increasingly digitised future using telephone consultations with expert patients.

\section{P179 A YEAR IN COVID - LOOKING AT THE MENTAL AND PHYSICAL HEALTH OF RESPIRATORY HIGH CARE UNIT (RHCU) STAFF THROUGHOUT THE COVID-19 PANDEMIC}

J Reece, R O'Neill, A Lal, SL Tan. Worcestershire Acute Hospitals NHS Trust, Redditch, Worcestershire, UK

\subsection{6/thorax-2021-BTSabstracts.288}

Our Respiratory High Care Unit (RHCU) was established in April 2020 in response to the COVID-19 pandemic, providing level-two care for COVID-19 patients. In one year, RHCU experienced a $54 \%$ mortality rate in patients who received Aerosol Generating Procedure.

There is concern among health-care workers of how the pandemic has affected mental health. Risk of suicide among female health professionals is $24 \%$ higher than female national average. $58 \%$ of doctors reported a detriment to their mental health since the start of the pandemic. ${ }^{1}$

We analysed impact on staffs' mental health after working on RHCU. Using a survey structured around Patient Health Questionnaire-9, staff retrospectively rated their mental health in April 2020, and commented on mental health in March 2021.

65 questionnaires were distributed. 53 (82\%) completed. $17 \%$ were doctors, $36 \%$ nurses, others include physiotherapists, pharmacists, administrative staff and cleaners. $62 \%$ worked on RHCU for $\geq 8$ months.

There was an increase in staff reporting a poor/fairly poor Mental Health Rating (MHR) (13\% in 2020, 30\% in 2021). 
49\% reported worsening MHR. Senior nurses (band 6 or above) appeared most affected, with $83 \%$ reporting a decrease in mental health, followed by doctors (56\%).

\begin{tabular}{|c|c|c|}
\hline RHCU Data & & \\
\hline \multicolumn{3}{|l|}{ Job role $(\%)$} \\
\hline - Senior doctor (registrar and above) & \multicolumn{2}{|l|}{8} \\
\hline - Junior doctor & \multicolumn{2}{|l|}{9} \\
\hline - Senior nurse (band 6 and above) & \multicolumn{2}{|l|}{11} \\
\hline - Staff nurse & \multicolumn{2}{|l|}{25} \\
\hline - HCA & \multicolumn{2}{|l|}{17} \\
\hline - Physio & \multicolumn{2}{|l|}{11} \\
\hline - Other (pharmacist, ward clerk, housekeepers, students) & \multicolumn{2}{|l|}{19} \\
\hline \multicolumn{3}{|l|}{ Time worked on RHCU (\%): } \\
\hline - 1-4 months & \multicolumn{2}{|l|}{25} \\
\hline - 4-8 months & \multicolumn{2}{|l|}{13} \\
\hline - 8-12 months & \multicolumn{2}{|l|}{62} \\
\hline \multicolumn{3}{|l|}{ Age of participants in years (\%): } \\
\hline$-18-25$ & \multicolumn{2}{|l|}{13.2} \\
\hline$-26-35$ & \multicolumn{2}{|l|}{34.0} \\
\hline$-36-45$ & \multicolumn{2}{|l|}{24.5} \\
\hline$-46-55$ & \multicolumn{2}{|l|}{18.9} \\
\hline$-56-65$ & \multicolumn{2}{|l|}{7.5} \\
\hline$->65$ & \multicolumn{2}{|l|}{1.9} \\
\hline \multirow[t]{2}{*}{ Analysis } & April & March \\
\hline & 2020 & 2021 \\
\hline \multicolumn{3}{|l|}{ Overall MHR (\%): } \\
\hline - Poor & 4 & 11 \\
\hline - Fairly poor & 10 & 19 \\
\hline - Average & 25 & 26 \\
\hline - Fairly good & 44 & 42 \\
\hline - Excellent & 17 & 2 \\
\hline Mood symptoms - reported as half the time or more (\%) & & \\
\hline - Depressed & 4 & 21 \\
\hline - Tearful & 6 & 27 \\
\hline - Anxious & 18 & 44 \\
\hline - Irritable & 18 & 40 \\
\hline $\begin{array}{l}\text { Anxiety coming into work experienced half the time or } \\
\text { more }(\%)\end{array}$ & 14 & 45 \\
\hline $\begin{array}{l}\text { Lack of motivation at work experienced half the time or } \\
\text { more }(\%)\end{array}$ & 10 & 30 \\
\hline Work-life balance - reported as half the time or more (\%) & & \\
\hline $\begin{array}{l}\text { - Worrying/thinking about patients outside of normal working } \\
\text { hours }\end{array}$ & 24 & 58 \\
\hline - Trouble falling asleep or sleeping too much & 33 & 55 \\
\hline - Feeling overly tired after a shift & 35 & 51 \\
\hline - Difficulty focusing on activities outside of work & 20 & 43 \\
\hline - Strain on personal relationships & 24 & 42 \\
\hline - Over/under eating & 29 & 54 \\
\hline - Exercising regularly & 52 & 50 \\
\hline Further analysis & & \\
\hline Impact on physical health (\%) & & \\
\hline - No impact & 10 & \\
\hline - Unsure & 15 & \\
\hline - Little impact & 49 & \\
\hline - Significant impact & 26 & \\
\hline Would you continue in your current job role? (\%) & & \\
\hline - Yes & 68 & \\
\hline - Unsure & 26 & \\
\hline - No & 6 & \\
\hline
\end{tabular}

There was an increase in negative mood symptoms (depressed, tearful, anxious and irritable) experienced half the time or more in 2021. Depressed mood had $>5$ folds increase $(4 \%$ in $2020,21 \%$ in 2021). 44\% staff reported feeling anxious half the time or more in $2021 \quad(18 \%$ in 2020).

$58 \%$ staff reported worrying about patients outside working hours half the time or more (20\% in 2020).

$75 \%$ reported some impact on their physical health. Worryingly, $67 \%$ senior nurses and 44\% doctors were unsure or would not continue in their job role.

Overall, participants aged 36-45 were most affected, 54\% reporting deterioration in MHR. Those aged 26-35 were most likely to consider leaving their current job role (39\%).

Our survey highlighted the ongoing need for mental health support for staff working through the pandemic. Staff recruitment and retention is another challenge.

\section{REFERENCE}

1. British Medical Association. Personal impact of the COVID-19 pandemic on doctors' wellbeing revealed in major BMA survey.

\section{P180 THE VIABILITY AND ACCEPTABILITY OF A RESPIRATORY PHYSIOTHERAPY WEEKEND LATE SHIFT SERVICE: A SERVICE EVALUATION}

${ }^{1}$ A Lockwood, ${ }^{1,2}$ E Douglas, ${ }^{1} \mathrm{~T}$ Harvey-Dunstan. ' University of Nottingham, Nottingham, UK; ${ }^{2}$ Nottingham University Hospitals NHS Trust, Nottingham, UK

\subsection{6/thorax-2021-BTSabstracts.289}

Background From July to November 2020, Nottingham City Hospital trialled a respiratory physiotherapy weekend late shift (RWLS) service in response to the COVID-19 Pandemic, running on Saturday and Sunday from 16:00 to 21:00. It aimed to decrease emergency call-outs, improve patient flow and improve timeliness of assessment and treatment. Literature relating to the efficacy of emergency and weekend physiotherapy services in the UK is limited due to inter-service variation. Local factors serve as barriers and facilitators to the provision of these services, justifying the need to evaluate services individually.

Aims To determine the viability and staff acceptability of the RWLS. Viability was defined as the success of the RWLS in meeting its three main aims, staff acceptance was defined as its perceived success.

Method Mixed-methods design. Quantitative data was collected prospectively using a bespoke data collection form completed by staff at the end of their shift. Data included; number of patients seen, area of speciality, emergency calls attended and number of discharges per shift. An online semistructured focus group with staff who worked the RWLS explored staff perceptions of the success and future acceptability of the RWLS, in depth.

Results The RWLS successfully reduced emergency call-outs by a mean of 1.06 call-outs per shift. Patient flow, measured by the number of interventions facilitating discharge was not directly improved, although staff felt discharge planning was initiated sooner. Staff felt the RWLS improved timeliness of assessment and treatment, but reported inefficiencies related to handover. The RWLS was well accepted by staff due to the shift's perceived benefits to patients, COVID-19 socialisation restrictions and overtime pay. Junior staff felt working the RWLS aided transition to emergency on-call work. 